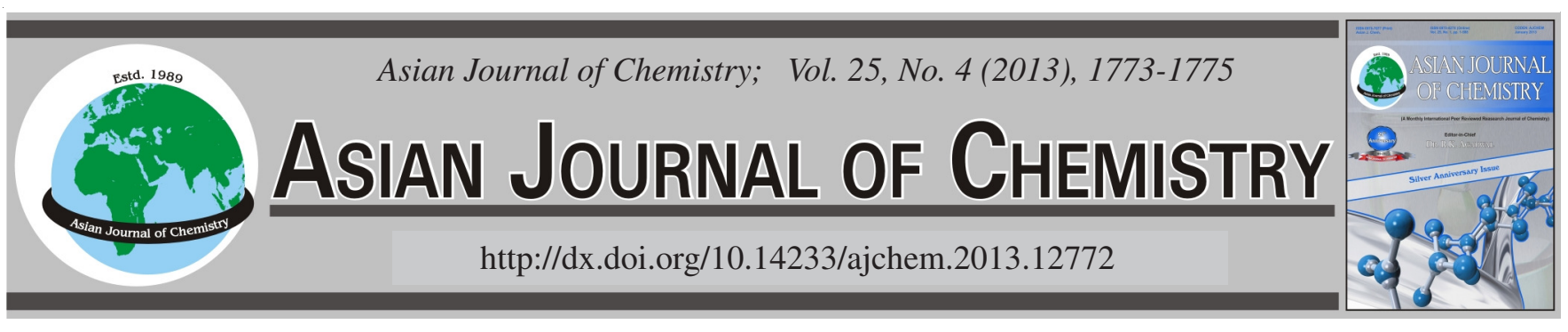

\title{
Dyeability Improvement of Cotton Fabric by Electron Radiation Treatment
}

\section{Abolfazl Davodiroknabadi ${ }^{1, *}$, Abosaeed Rashidi $^{2}$, Mohammad Mirjalili $^{3}$ and Salar Zohoori ${ }^{3}$}

\author{
${ }^{1}$ Department of Design and Clothing, Yazd Branch, Islamic Azad University, Yazd, Iran \\ ${ }^{2}$ Textile Section, Science and Research Campus, Tehran Branch, Islamic Azad University, Tehran, Iran \\ ${ }^{3}$ Department of Textile Engineering, Yazd Branch, Islamic Azad University, Yazd, Iran
}

*Corresponding author: E-mail: davodi@gmail.com

Electron radiation is one of the finishing processes that can be used in dry environments and doesn't need any chemical materials and use for improving of textiles properties and synthetic polymers. Another important improvement of this finishing method is no need of water, less wastewater without any ecological problems. In this paper, the samples treated by 5, 10, 15, 20, 25, 30 and 35 KGy radiation intensities and they dyed with C.I. Direct Red 23. Also the physical properties of samples such as elongation, work of rupture and strength were investigated. The results show a significant improvement in dyeability of treated samples. Meanwhile, in this study the physical properties of samples investigated in order to find the best and ideal irradiation intensity.

Key Words: Electron radiation, Cotton, Dyeability, Physical properties.

\section{INTRODUCTION}

Some atoms contain impermanent fundamental ingredients. These atoms irradiate spontaneous and convert to another atoms with different chemical identity. This process called radio activities. Natural radioactive materials irradiate three rays i.e., $\alpha, \beta$ and $\gamma$. $\alpha$ Ray contain ingredients that each of them has two protons and two neutrons. The $\alpha$ ray scintillate with speed of $16000 \mathrm{k} / \mathrm{s}$ from radioactive atom and comport 2 possitive electrical charge and its weight is about tantamount of 4 protons. $\beta$ Ray is electrical flow that revolves with speed of $128000 \mathrm{k} / \mathrm{s}$. $\beta$ ray is a kind of light with high energy and without any electrical charge ${ }^{1}$.

The meaning of producing accelerator is providing a strip of shot for experiment that its energy and intensity can controlled. Different accelerators can give enough kinetic energy to protons and electrons in order to overcome on nucleus electrostatic repellency. The electron accelerator, produce electron in energy range of low or high. The applicable range of energy in industry is between $0.15-10 \mathrm{Mev}$. There is no report available in literature on the application for low energies (because of its lowest electron diffusion in to materials) and high energies over $10 \mathrm{Mev}$ (because of its ability to radiate). There are different methods for producing high-energy electron irradiation and accelerators. The low energy electrons in vacuum area and in powerful electrical field, get velocity and then they land on sample. The difference is that industrial accelerators have high powerful electrical field. The main parameter of electron accelerators are: voltage, strap speed (that determine energy of electrons and its diffusion) and intensity (that show number of produced electron per second).

The output power of irradiation is equal to multiple of voltage and intensity that determinant produced potency ${ }^{1}$. The main application of irradiation treatment is processing polymer products in order to modified physical and chemical properties. These applications are: crosslinks of plastic films, cable insulator, airplane landing gear particles and physical-mechanical improvement of rubbers that strengthen with staple fibers, electrical accelerators for medical sterilizations such as bands. They also use for antibacterial of meat, chickens and corns. On the other hand we can use accelerators for antibacterial of hospitals, city rubbishes, sewage, destroy toxic materials of water and soil and for compress acidic gases, sulfur and nitrogen oxides of burnings $s^{2-4}$.

In textile and polymeric material, all physical and chemical properties influenced by parameters such as kinds of molecules chains, number and kind of lateral bounds, style of molecules chains, orientation and crystalline percent of samples. Therefore, irradiation treatment, because of high electrons energy, can change the properties of polymer fibers by changing their structure.

The irradiation treatment has effect on polymeric fiber structure by creating active radicals on polymer molecular chain or on its additional materials and also by creating 
crosslinks and effect on crystalline phases of polymer structure ${ }^{5}$. It must be mention that irradiation treatment, like cold plasma treatment, is a good method of natural settlement because of doing in dry environments without using chemical materials and can be economically commodious.

In this paper, for investigating of improving of dyeability of cotton fiber, irradiation treatment with electron radiation in various intensities used and so the dyeability of samples calculated. Moreover, the physical properties of samples investigated for decision about criterion of effect of irradiation treatment.

\section{EXPERIMENTAL}

In this paper our bleached cotton fabric with linear density of warp/weft 20/1 Ne, warp compression of 24/1 Cm, weft compression of $20 / 1 \mathrm{Cm}$, with weight of $136 \mathrm{~g} / \mathrm{m}^{2}$, with taffeta L1/1, treated by electron radiation TT200, IBA company, Belgium. The device has four horizontal and vertical outputs and can support the energy level of $5000000 \mathrm{ev}$ and 10000000 ev (Fig.1).

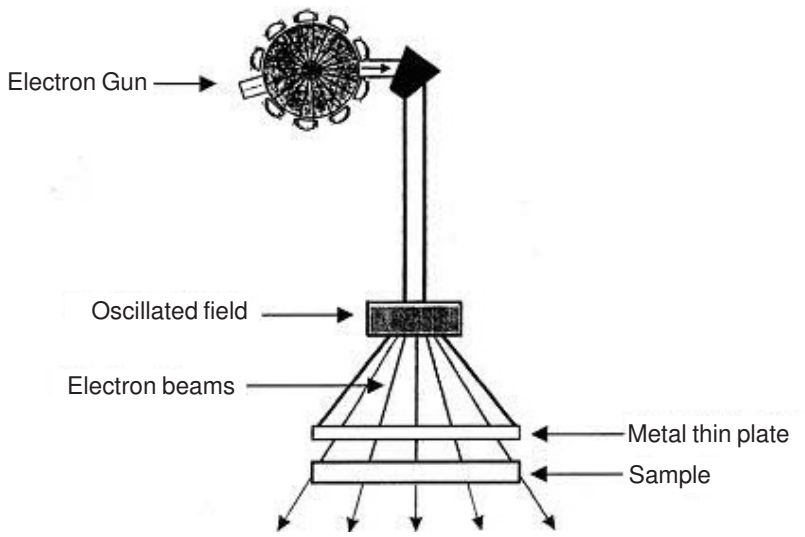

Fig. 1. Schematic of electron accelerator, path of high-energy electrons and place of specimen

The dimension of samples was $90 \mathrm{~cm} \times 300 \mathrm{~cm}$ and they putted on mobile halter and treated with 5, 10, 15, 20, 25, 30, $35 \mathrm{KGy}$ intensities. During this treatment, the electric field with energy of $10000000 \mathrm{ev}$ irradiates the high-energy electrons from thin metal plate in to samples in the vacuum place.

The primary sample and the treatment samples putted in the dye bath of $2 \%$ direct red 23, $20 \mathrm{~g} / \mathrm{L}$ sodium chloride and L:R 40:1, in order to investigate the effect of irradiation treatment on dyeability of samples. Dyeing started at $45^{\circ} \mathrm{C}$ and it growth $2{ }^{\circ} \mathrm{C} / \mathrm{min}$ until $100^{\circ} \mathrm{C}$ and at this temperature, dyeing continued for $45 \mathrm{~min}$. At the end, the adsorption of wastewater calculated by spectrophotometer model 100 Cary, Varien UV-VIS, in $\lambda_{\max }=523 \mathrm{~nm}$ and the exhaustion calculated by equation 1 :

$$
\% \mathrm{E}=[\mathrm{A}-(\mathrm{B}+\mathrm{C})] / \mathrm{A}
$$

where, $\% \mathrm{E}$ : percent of exhaustion; $\mathrm{C}$ : concentration of existing dye in washing wastewater $(\mathrm{g} / \mathrm{L})$; $\mathrm{B}$ : concentration of existing dye in wastewater $(\mathrm{g} / \mathrm{L})$; A: total dye concentration $(\mathrm{g} / \mathrm{L})$.

\section{RESULTS AND DISCUSSION}

The results of adsorbing dye of primary cotton and treated cotton are shown in Table-1 and Fig. 2.
TABLE-1

DYEING PARAMETERS CHANGING OF PRIMARY AND TREATED SAMPLES IN DIFFERENT INTENSITIES

\begin{tabular}{ccccc}
\hline $\begin{array}{c}\text { Exhau- } \\
\text { stion }(\%)\end{array}$ & $\begin{array}{c}\text { Remain dye in } \\
\text { wastewater }(\mathrm{g} / \mathrm{L})\end{array}$ & $\begin{array}{c}\text { Dye adsor- } \\
\text { ption }(\mathrm{g} / \mathrm{L})\end{array}$ & $\begin{array}{c}\text { Wastewater } \\
\text { adsorption }\end{array}$ & $\begin{array}{c}\text { Intensity } \\
(\mathrm{KGy})\end{array}$ \\
\hline 86.25 & 0.055 & 0.345 & 0.833 & 0 \\
90.00 & 0.041 & 0.36 & 0.623 & 5 \\
92.50 & 0.03 & 0.37 & 0.459 & 10 \\
95.00 & 0.017 & 0.38 & 0.269 & 15 \\
90.00 & 0.043 & 0.36 & 0.664 & 20 \\
88.25 & 0.047 & 0.353 & 0.714 & 25 \\
88.00 & 0.048 & 0.352 & 0.732 & 30 \\
87.75 & 0.049 & 0.351 & 0.747 & 35 \\
\hline
\end{tabular}

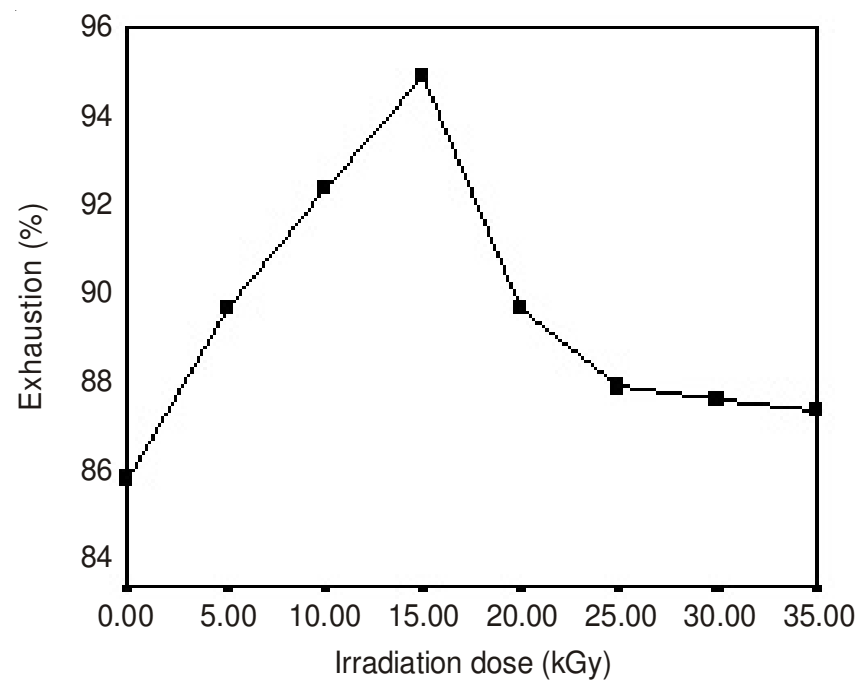

Fig. 2. Exhaustion changing toward intensity of irradiation treatment

During the study, the physical properties of samples such as strength, elongation and work of rupture investigated in order to identify the effect of electron irradiation treatment on application properties of cotton for identify the ideal rang of treatment. So, for this purpose, samples of $5 \mathrm{~cm} \times 25 \mathrm{~cm}$ prepared and tested by Instron strength device. The results are show in Table-2 and Fig. 3.

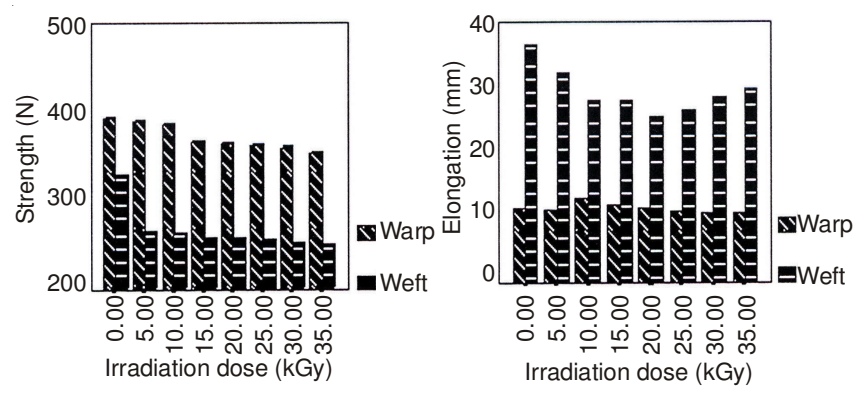

Fig. 3. Changing of (a) strength (b) breaking elongation toward intensity of irradiation treatment in warp and weft

\section{Conclusion}

By comparison of obtained results of exhaustion, it observe that by increasing the intensity of irradiation up to 15 $\mathrm{KGy}$, the exhaustion of cotton increase quickly but the intensities between $15 \mathrm{KGy}$ to/and $35 \mathrm{KGy}$, reduced the adsorption; although these adsorption is more than pure and 
TABLE-2

PHYSICAL PROPERTIES CHANGING OF TREATED SAMPLES IN DIFFERENT INTENSITIES

\begin{tabular}{ccccccc}
\hline $\begin{array}{c}\text { Weft work of } \\
\text { rupture }(\mathrm{cN} . \mathrm{cm})\end{array}$ & $\begin{array}{c}\text { Warp work of } \\
\text { rupture }(\mathrm{cN} . \mathrm{cm})\end{array}$ & $\begin{array}{c}\text { Weft elongation } \\
(\mathrm{mm})\end{array}$ & $\begin{array}{c}\text { Warp elongation } \\
(\mathrm{mm})\end{array}$ & $\begin{array}{c}\text { Weft strength } \\
(\mathrm{N})\end{array}$ & $\begin{array}{c}\text { Warp strength } \\
(\mathrm{N})\end{array}$ & $\begin{array}{c}\text { Intensity } \\
(\mathrm{KGy})\end{array}$ \\
\hline 710.365 & 322.150 & 36.675 & 11.360 & 326.681 & 392.993 & 0 \\
541.205 & 298.738 & 32.250 & 11.171 & 264.946 & 390.317 & 5 \\
488.013 & 386.925 & 27.950 & 12.980 & 262.009 & 386.925 & 10 \\
476.860 & 350.783 & 27.833 & 11.860 & 257.836 & 365.929 & 15 \\
463.620 & 323.735 & 25.400 & 11.420 & 256.287 & 362.786 & 20 \\
450.720 & 283.460 & 26.560 & 10.820 & 255.284 & 360.698 & 25 \\
362.220 & 269.345 & 28.350 & 10.551 & 250.982 & 359.190 & 30 \\
314.580 & 265.880 & 29.700 & 10.500 & 250.378 & 353.660 & 35 \\
\hline
\end{tabular}

untreatment sample (Fig. 2). It must be mention that the effect of irradiation treatment on cotton dyeability is the same as mercerization of cotton and the adsorption and lucidity of dyed samples after irradiation treatment is look like fabric mercerization. It seems that some of the proteins and waxes of fabric broken under irradiation and remove through washing, so the ability of dye diffusion increase.

On the other hand, by electron irradiation of samples, kinetic energy of sample chains increase and the hydrogen bounds of chain groups break and thus by rotating of chains, hydroxyl groups come to surface of specimen, therefore the dye adsorption of samples increase because of increasing of possibility of hydrogen bound between dye and surface of fiber. The other reason of increasing dye adsorption is increasing of amorphous area of sample because of physical changing of sample by irradiation.

For strength, the changing range of strength is low, up to $10 \mathrm{KGy}$ intensity, and suddenly decrease in intensity of 15 $\mathrm{KGy}$ and then the strength rang is constant. This stable range of strength is because of cellulose molecular chain break in intensity of $10 \mathrm{KGy}$ and above. The changing of elongation and work of rupture in different intensities depend on break of molecular chains and bridge of crosslinks.

In general, we can report that irradiation treatment in 15 $\mathrm{KGy}$ is a modified method/treatment for improving dyeability of cotton fabric that the physical properties are insensible.

\section{REFERENCES}

1. C.E. Mortimer, Chemistry, A Conceptual Approach, edn 3, (1975)

2. A.S. Bashar, A. Mubarak, A. Khan and K.M. Idriss Ali, J. Appl. Polym. Sci., 63, 13 (1997).

3. M.R. Cleland, Economic Radiat. Proces., p. 115 (1995).

4. M. Papini, Appl. Spectrosc., 43, 1475 (1989).

5. A. Rashidi, M. Mirjalili and M. Ghoranneviss, Application of Low Temperature Plasma to Modification of Polypropylene, Joint Conference of the $12^{\text {th }}$ International Toki Conference on Plasma Physics and Controlled Nuclear Fusion, PI-29, Ceratopia Japan, vol. 83, pp. 11-14, (December 2001). 